\title{
Twenty-one Days of Solitude
}

\author{
Hemanshu Prabhakar@
}

\begin{abstract}
As the world is now gradually coming out of the "lockdown" phase, one can expect a change in the demographics and epidemiology of trauma. With traffic back on roads and shifting life again towards "normalcy", it is imperative to carry out introspection and see how we can stop trauma from reaching its pre-COVID levels.

Keywords: COVID-19, Lockdown, Pandemic, Trauma.

Indian Journal of Critical Care Medicine (2021): 10.5005/jp-journals-10071-23757
\end{abstract}

The last decade ended grotesquely and the mortals will remember it for years to come. The effluvia of the invisible contagion irreversibly transposed the lives of humans. While the coronavirus was spreading its deathly spikes rampantly, human intelligentsia and researchers continuously looked for remedial measures. Several pharmacological measures were tried, but none to efficacy. Social distancing was thought to be an effective way in preventing the spread of the disease. In this regard, governments of several countries implemented periods of lockdown in their geographical regions. It would not be incorrect to say that the months of April-May 2020 observed nationwide lockdown in most countries across the globe.

Lockdown during the pandemic had an impact on both, the nature and volume of hospital admissions, especially those related to trauma. This rundown was noted globally and was not restricted to the Indian subcontinent. The impact of societal restrictions and lockdown on trauma admissions during the lockdown was reported by Jacob et al., from Australia. ${ }^{1}$ There was a $23-34 \%$ decrease in the monthly average trauma admissions during March-April 2020 compared with previous years 2016-2019. Also, there was a $40-52 \%$ and $13-29 \%$ decrease in admissions due to road traffic collisions and falls, respectively. Europe also remained an epicenter of this pandemic. Fahy et al. analyzed the variations in volume and nature of trauma presentations during the lockdown in Ireland. ${ }^{2}$ All emergency department presentations between 27 March 2019 to 27 April 2020 and 27 March 2020 to 27 April 2020 were cross-referenced against the National Integrated Medical Imaging System-Picture Archiving Communication System (NIMIS-PACS) radiology system to identify those with radiologically proven skeletal trauma. They found a reduction by $21 \%$ in radiologically proven trauma when compared with the same period last year. They also noted a $40 \%$ reduction in trauma admissions during the lockdown. There was a $60 \%$ reduction in sports-related and road traffic accident-related injuries. However, a rise by $17 \%$ was observed in patients sustaining trauma because of domestic causes.

Another interesting piece of data was shared by a European group, where the authors also noted a reduction in trauma admissions in the lockdown phase, though they recorded an increase in road traffic accidents. ${ }^{3}$ Chiba et al., very categorically advised that it was "safer at home" and they noted a significant reduction in automobile accidents. Ironically, they found an increase in other types of trauma, such as gun-shot injuries, suicides, and ground-level falls in the elderly. ${ }^{4}$
Department of Neuroanaesthesiology and Critical Care, Neurosciences Centre, All India Institute of Medical Sciences (A.I.I.M.S.), New Delhi, Delhi, India

Corresponding Author: Hemanshu Prabhakar, Department of Neuroanaesthesiology and Critical Care, Neurosciences Centre, All India Institute of Medical Sciences (A.I.I.M.S.), New Delhi, Delhi, India, Phone: +91 9818727319, e-mail: prabhakaraiims@yahoo.co.in

How to cite this article: Prabhakar H. Twenty-one Days of Solitude. Indian J Crit Care Med 2021;25(3):249-250.

Source of support: Nil

Conflict of interest: None

The lockdown impacted the ophthalmic injuries too. A $53 \%$ reduction in emergency eye department attendance was noted during the lockdown, by Poyser et al. ${ }^{5}$ They believe that awareness of hand hygiene practices, social distancing measures, and school closures could have an indirect role in reducing the spread of infective conjunctivitis. In a study from Brazil, the authors questioned if the lockdown during pandemic influenced the oral and maxillofacial surgery services? ${ }^{6}$ They found a $52.27 \%$ decrease in the total number of patients and a $76.34 \%$ decrease in the total consultations of the service of oral and maxillofacial surgery during the lockdown. They concluded that the lockdown was an effective way to reduce the transmission of the COVID-19, the hospital usage, and occupation. In relation to the pandemic, the findings of Slullitel et al. are noteworthy. ${ }^{7}$ They noted that despite testing negative for coronavirus, patients during COVID times were less active and frailer than pre-COVID time's patients, depicting an epidemiological shift that was associated with a higher mortality rate.

It must be mentioned here, that the lockdown affected not only the adults but the pediatric population too. Chong et al. highlighted a significant decrease in infection-related presentations in pediatric patients, likely attributed to the lockdown, and showed that the relative proportion of trauma-related attendances increased, in their study. ${ }^{8}$ In another study on the pediatric population, Kuitunen et al., found results strongly suggesting social distancing and other lockdown strategies as effective in slowing down the spread of common respiratory viral diseases and decreasing the need for hospitalization among children. ${ }^{9}$ Sheridan et al. also concluded from

(c) Jaypee Brothers Medical Publishers. 2021 Open Access This article is distributed under the terms of the Creative Commons Attribution 4.0 International License (https://creativecommons.org/licenses/by-nc/4.0/), which permits unrestricted use, distribution, and non-commercial reproduction in any medium, provided you give appropriate credit to the original author(s) and the source, provide a link to the Creative Commons license, and indicate if changes were made. The Creative Commons Public Domain Dedication waiver (http://creativecommons.org/publicdomain/zero/1.0/) applies to the data made available in this article, unless otherwise stated. 
their study that the COVID-19 pandemic significantly reduced the number of acute traumatic pediatric admissions and procedures performed in our level I trauma center, likely because of a reduction in school days. ${ }^{10}$

Psychological and mental trauma is another aspect that was largely impacted upon by the ongoing pandemic. Italy was among the countries worst affected by the pandemic. Quarantine was associated with post-trauma stress symptoms, such as depression, insomnia, anxiety, and adjustment disorders, as reported by an Italian group. ${ }^{11}$

In India too, lockdown affected the routine and influenced the lives of the citizens. Here, we have interesting data collected by Hazra et al., where the authors compared a spectrum of variables and outcome of trauma victims who presented to their emergency department during April 2020, that is, the lockdown period, to a similar season matched control arm of April 2018, the non-lockdown period. ${ }^{12}$ As anticipated, they found a decline in the prevalence of trauma during the lockdown. In the first study of its kind, reported from India, the authors found a significant reduction in the proportion of trauma patients, especially those under the influence of alcohol. There was an absolute increase in fall on level ground, domestic trauma, and burn injuries.

As the world is now gradually coming out of the "lockdown" phase, one can expect a change in the demographics and epidemiology of trauma. With traffic back on roads and shifting life again towards "normalcy", it is imperative to carry out introspection and see how we can stop trauma from reaching its pre-COVID levels.

Stay home, stay safe!

\section{OrCID}

Hemanshu Prabhakar (․ https://orcid.org/0000-0001-7830-3296

\section{References}

1. Jacob S, Mwagiru D, Thakur I, Moghadam A, Oh T, Hsu J. Impact of societal restrictions and lockdown on trauma admissions during the COVID-19 pandemic: a single-centre cross-sectional observational study. ANZ J Surg 2020;90(11):2227-2231. DOI: 10.1111/ans.16307.

2. Fahy S, Moore J, Kelly M, Flannery O, Kenny P. Analysing the variation in volume and nature of trauma presentations during
COVID-19 lockdown in Ireland. Bone Jt Open 2020;1(6):261-266. DOI: 10.1302/2046-3758.16.BJO-2020-0040.R1.

3. Ajayi B, Trompeter A, Arnander M, Sedgwick P, Lui DF. 40 days and 40 nights: Clinical characteristics of major trauma and orthopaedic injury comparing the incubation and lockdown phases of COVID-19 infection. Bone Jt Open 2020;1(7):330-338. DOI: 10.1302/2633-1462.17. BJO-2020-0068.R1.

4. Chiba $H$, Lewis $M$, Benjamin ER, Jakob DA, Liasidis $P$, Wong MD, et al. "Safer at home": the effect of the Covid-19 lockdown on epidemiology, resource utilization and outcomes at a large urban trauma center. J Trauma Acute Care Surg 2020; Publish Ahead of Print. DOI: 10.1097/TA.0000000000003061.

5. Poyser A, Deol SS, Osman L, Kuht HJ, Sivagnanasithiyar T, Manrique R, et al. Impact of COVID-19 pandemic and lockdown on eye emergencies. Eur J Ophthalmol 2020:1120672120974944. DOI: $10.1177 / 1120672120974944$.

6. Figueiredo LB, Araújo SCS, Martins GH, Costa SM, Amaral MBF, Silveira $R L$. Does the lockdown influence the oral and maxillofacial surgery service in a level 1 trauma hospital during the novel coronavirus 2019 (COVID 19) pandemia? J Craniofac Surg 2020. DOI: 10.1097/ SCS.0000000000007054. Epub ahead of print.

7. Slullitel PA, Lucero CM, Soruco ML, Barla JD, Benchimol JA, Boietti $\mathrm{BR}$, et al. Prolonged social lockdown during COVID-19 pandemic and hip fracture epidemiology. Int Orthop 2020;44(10):1887-1895. DOI: 10.1007/s00264-020-04769-6.

8. Chong SL, Soo JSL, Allen JC Jr, Ganapathy S, Lee KP, Tyebally A, et al. Impact of COVID-19 on pediatric emergencies and hospitalizations in Singapore. BMC Pediatr 2020;20(1):562. DOI: 10.1186/s12887-02002469-z.

9. Kuitunen I, Artama M, Mäkelä L, Backman K, Heiskanen-Kosma T, Renko M. Effect of social distancing due to the COVID-19 pandemic on the incidence of viral respiratory tract infections in children in Finland during early 2020. Pediatr Infect Dis J 2020;39(12):e423-e427. DOI: $10.1097 /$ INF.0000000000002845.

10. Sheridan GA, Nagle $M$, Russell $S$, Varghese $S$, O'Loughlin PF, Boran $S$, et al. Pediatric trauma and the COVID-19 pandemic: a 12-year comparison in a level-1 trauma center. HSS J 2020;16(Suppl 1):1-5. DOI: $10.1007 /$ s11420-020-09807-y.

11. Rossi R, Socci V, Talevi D, Mensi S, Niolu C, Pacitti F, et al. COVID-19 pandemic and lockdown measures impact on mental health among the general population in Italy. Front Psychiatry 2020;11:790. DOI: 10.3389/fpsyt.2020.00790.

12. Hazra D, Jindal A, Fernandes JP, Abhilash KPP. Impact of the lockdown due to COVID 19 pandemic on the spectrum and outcome of trauma in India. Indian J Crit Care Med 2021;25(3):273-278.. 